International Journal of Engineering \& Technology, $7(4.5)(2018) 188-192$
International Journal of Engineering \& Technology
Website $:$ www.sciencepubco.com/index.php/IJET
Research paper

\title{
Development of a Multi-Motor Power System for Vehicles Converted to Electric
}

\author{
Correa Zapata Sebastian ${ }^{1}$,Vergara Crismatt Carlos $^{2}$, Rico Mesa Edgar ${ }^{3}$ \\ ${ }^{1}$ SENA, Medellin, Colombia \\ ${ }^{2}$ SENA, Medellin, Colombia \\ ${ }^{3}$ SENA, Medellin, Colombia \\ *Corresponding author E-mail:scorreaz@sena.edu.co, cavergara91@misena.edu.co,emrico@sena.edu.co
}

\begin{abstract}
The GACIPE research group has been developing a project focused on the conversion of an internal combustion car to an electric one, implementing a mechanical and electronic development with the objective of implementing new technologies in the automotive sector by designing drivers to control the speed of multiple $2.2 \mathrm{kw}$ DC motors with a new trigger procedure of the power devices. This project is a small contribution to reducing the effects of climate change.
\end{abstract}

Keywords: Power, Multiplexation, Conversion, Multi-motor.

\section{Introduction}

At the beginning of 1990 , various organizations were set up to study the pollution problems generated by the emission of nitrogen oxide and carbon monoxide [1].

In the first two decades of the 21 st century, the $\mathrm{CO} 2$ production shows a continuous increasing that changed in 2015 as follows:

China and the United States reduced their emissions by $0.7 \%$ and $2.6 \%$, respectively.

Russian Federation and Japan decreased $3.4 \%$ and $2.2 \%$, although India and the European Union increased by $5.1 \%$ and $1.3 \%$.

The increase of $15.2 \%$ was in sources of electricity alternative.

The European Union led the Paris Agreement on Climate Change.

This Agreement was adopted by approximately 194 countries [2].

Then, the Paris Agreement promoted the development of projects focused on the achievement of clean energy sources (renewable energy) and high efficiency, although their high cost has not managed to replace traditional fuels. Therefore, the Organization of the United Nations adopts the decisions of the Paris Agreement. [3].

However, the government that has made the most effort to lead to the reduction of polluting factors in the atmosphere since The Paris agreement in 2015 is the European Union. The European Union had proposed in the last decade to reduce the production of $\mathrm{CO} 2$ for the year 2021 to $95 \mathrm{~g} / \mathrm{km}$. Although, the European countries are far from the proposed goal. But, the number of electric vehicles was incremented [4].

In [5] it is stated that a large part of greenhouse gas emissions in Colombia is related to the transportation sector whose contribution to the country's emissions corresponds to approximately $17 \%$. It implies the development of science and technology activities as one of the strategies to find technological solutions that mitigate the current impact of gas emissions. The government has set a goal of $20 \%$ reduction of gas emissions by the year 2030 .

Therefore, the government is aware of the harmful effects of the gas emissions on the planet and it is implementing new policies and regulations to reduce the gas emissions, and promoting clean energy.

At the moment, GACIPE group has developed a project on electric vehicles focused on the conversion of used cars to electrical, designing and developing own technologies for the power module, strategic component to dose the energy applied to the motors that drive the vehicle.

This paper has the following chapters:

Approach to power system in electric vehicles: this chapter presents the technologies for developing electric vehicle projects.

Conceptual Framework: this chapter defines theoretical concepts related to the project.

Results: this chapter presents the scope of the prototype.

Data analysis: this chapter shows an interpretation of the data obtained in the start-up of the prototype.

\section{Approach to Power Systems in Electric Ve- hicles}

There is a series of works made in the last 5 years on technological developments in electric vehicles. It presents below.

In [6] and [14] presents the importance, the efficiency of using electronic power converters as well as new designs for the management of motors for the development of electric cars.

In [7] a study on the generation of electromagnetic interference caused by electronic power equipment in the electric vehicle is made. 
In [8] reveals the difficulties of the use of hydrogen as a gasoline replacement. Additionally, It presents a study of the types of electric cars existing in the market.

In [9] presents a paper on electric vehicles using ultracapacitors to easy the transients produced the motors.

In [10] proposes the trends of battery charging strategies for electric vehicles in Europe and possible scenarios for renewable energy costs.

In [11], [15], [16] shows the modeling, simulation, and experimentation of the DC motor of an electric car. The aspects are the dynamic response of the motor and charge characteristics of the battery.

In [12] presents some case studies on the sustainability of the production of electric vehicles. In [13] poses the integration in the automotive market worldwide.

\section{Conceptual framework}

\subsection{Converters/DC (Chopper)}

It is an electronic device that converts a fixed voltage direct current (DC) power source to a variable voltage (DC) source. The converters (DC / DC) use in the control of traction motors of electric cars, electric trams, forklifts and lifts [17].

\subsection{Snubber net}

The Switching aid circuits are commonly known as "snubber" according to [18]. They consider as a set of components passive or active. They incorporate into the power circuit to reduce the electrical stress during commutations in the semiconductor device. They ensure a safe working regime. The RCD voltage circuit presents in Figure 4.

When the transistor goes into conduction, the energy stored in the capacitor circulates through the resistance R. Also, the capacitor C should be without charge during the transistor conduction. The next commutation period starts with typical initial conditions (zero voltage).

Therefore, the RC time constant must be less than the commutation period and must be sufficient to allow the capacitor $\mathrm{C}$ to charge and discharge in each duty cycle. The RCD circuit intervenes only during commutations.

\subsection{Noises and interferences}

It means any unwanted voltage or current component that overlaps or interferes with the operation of the circuit. The noise can be both external and internal. It eliminates by signal filtering methods [19].

\section{Results}

\subsection{Mechanical design}

\subsubsection{Structure or chassis}

It starts with the redesign of the structure of a demonstrative car (figure 1). The internal combustion motor and its accessories disassemble for the adaptation of the necessary space. The electric motors situate free space.

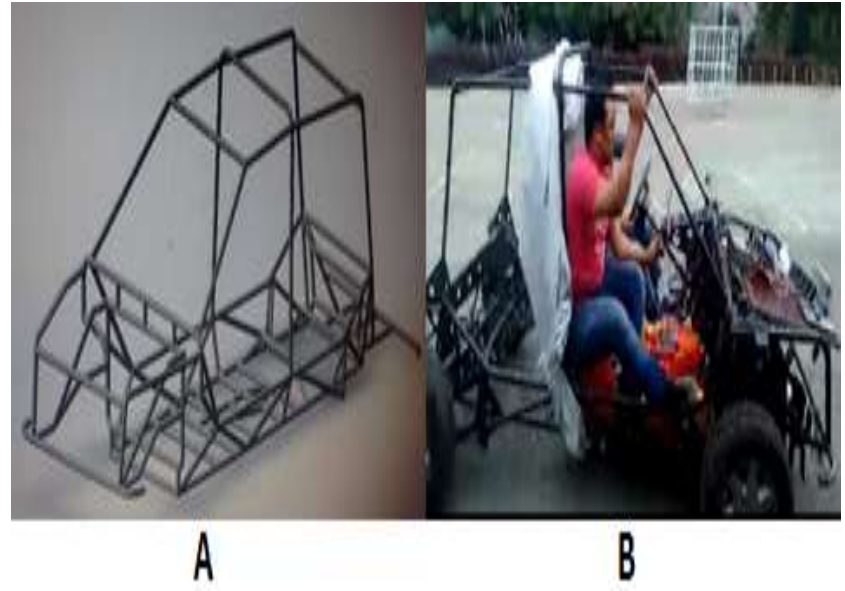

Fig. 1::Model and Assembly of the final Structure: A) Model, B) Assembly

\subsubsection{Motion transmission}

The mechanical system of movement transmission is composed of a multi-motor coupling and a gearbox. The ratio of the pinions (steel sprockets AISI / SAE 8620) connecting the motors and the gearbox is $1-1$.

\subsubsection{Multi-motor coupling}

It is an arrangement of steel sprockets (AISI / SAE 8620) developed specifically for high torque mechanical tensions and is responsible for joining the two DC motors (see Figure 2) with the transmission box. That way, the functioning of the motor is as follows:

- It is used only one motor at maximum speeds.

- It is used the two motors to increase torque at slow speeds.

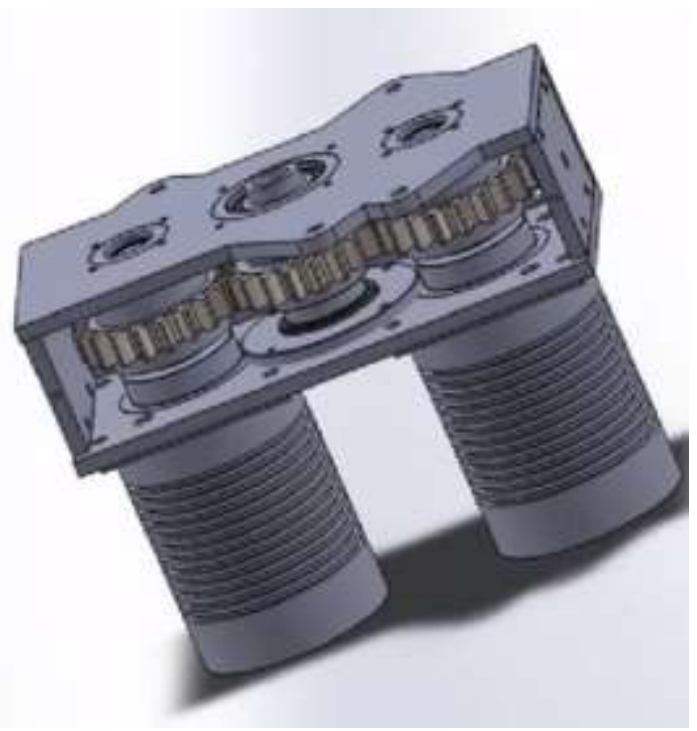

Fig. 2: Model of Multi-motor coupling

\subsubsection{Transmission box}

The system that switches the pertinent mechanical relation to obtain the required speed according to the moment. The project employs a Suzuki Swift transmission box of 5 speed.

Although, the auto conserves three pedals control (brake, clutch, and accelerator). The intervention makes in the combustion process. 


\subsection{Electronic design}

\subsubsection{Power transistor}

The characteristics of the load specified according to the operating voltage and the maximum current such as:

-The maximum current of the motor $114 \mathrm{~A}$

-The operating voltage $24 \mathrm{~V}$

Therefore, it is necessary to find a transistor that complies with such specifications. The power that dissipates is the lowest possible. the motor receives the highest power possible. The transistor reduces the losses due to temperature.

In the load line (see figure 3) of the IXFN 520 transistor, the dissipation power is low (approximately $17 \mathrm{w}$ ). The power in the motor is maximum. The voltage $V_{G S}$ is 15 volts.

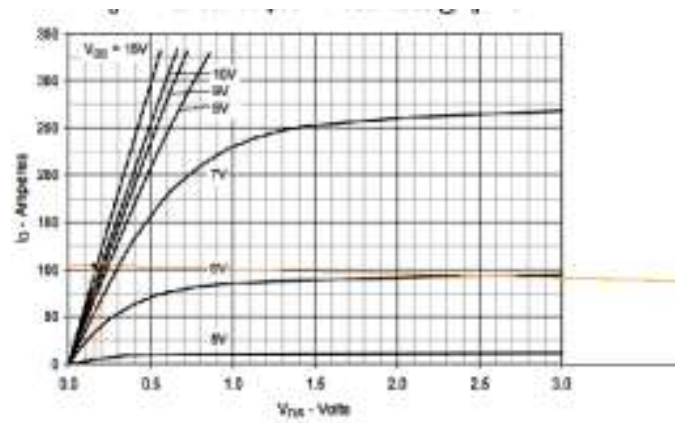

Fig. 3: Volt-Ampère characteristics of IXFN 520

In this process, the power driver was designed and developed to control the speed of the motor through a DC / DC converter (chopper), manufactured with 5 MOSFET transistors (IXFN520) connected in parallel.

\subsubsection{Snubber network}

The snubber network (figure 4) is designed based on the following characteristics:

- The load response of the capacitor is related to the minimum time of deactivation of the transistor (t_off).

- The discharge response of the capacitor is related to the minimum activation time of the transistor ( $\mathrm{t}$ on)

- The diode (D) must have an activation and deactivation response equal to or less than the activation and deactivation response of the transistor.

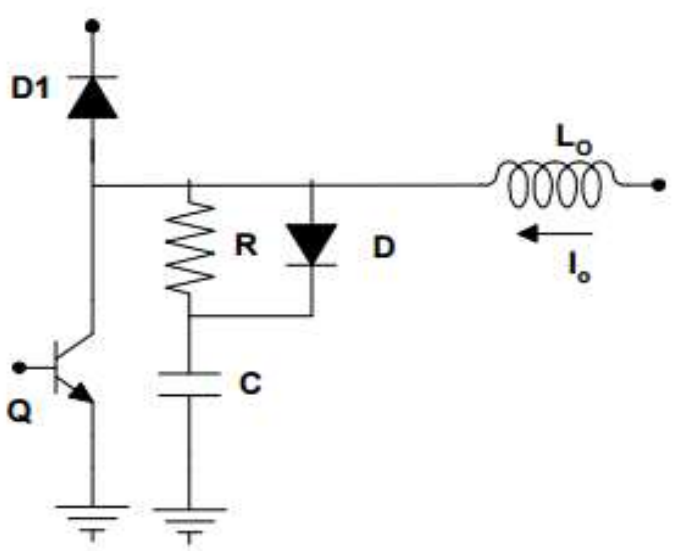

Fig. 4: Snubber network RCD

Figure 4 explains the basic operation of the RCD circuit commutation. The transistor is turned off. The current circulates by the coil $\mathrm{L}$, the diode $\mathrm{D}$ and the capacitor $\mathrm{C}$. The voltage in the capacitor will increase until the supply voltage of the circuit. The main diode D1 would enter in conduction take the current from the coil.

The calculation for determining the capacitance value of the capacitor is shown to the continuation.

$c=\frac{2 I_{0} t_{0}}{9 v s s}$

The calculation of the value of the resistance (R) shown to the continuation

$\mathrm{R}=\frac{\mathrm{t}_{\mathrm{on}}}{5 \mathrm{c}}$

\subsubsection{Card design PCB}

Design criteria apply to aspects as conductivity, noise elimination, the position of tracks and the elements on the PCB [20].

In addition to the design techniques mentioned above, it was necessary to incorporate passive second order type (LC) filters. It was sought to improve the conditions or optimum levels of tension for the control systems. The tantalum and polyethylene condensers use for stability in the signal at the time of switching.

\subsubsection{Design and development of the control module}

For the design of the control module and definition of the microcontroller, the number of actuators and sensors to be used taken into account in order. It used as a second microcontroller responsible for generating the five PWM signals. It is important, the implementation of noise-free sources (see figure 5 ).

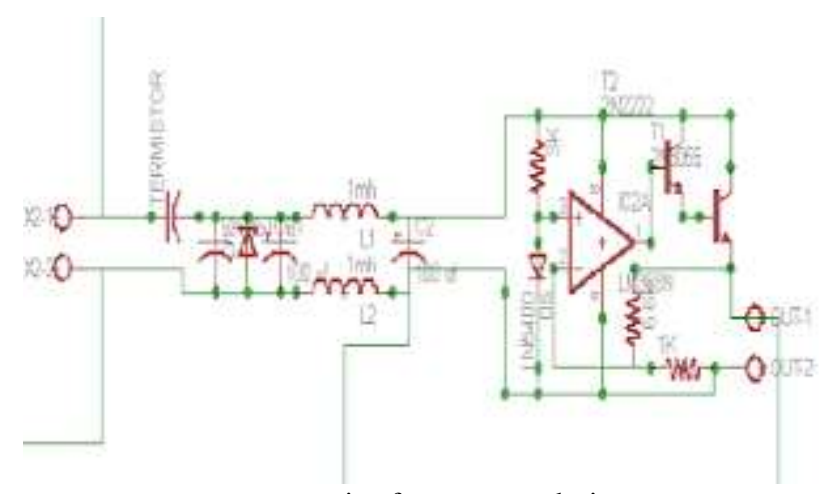

Fig. 5: noise-free sources design

The source implemented a circuit with following components: A thermistor to avoid current peaks.

A Zener diode to avoid voltage peaks.

Tantalum and polystyrene condensers added to the power supply.

\subsubsection{Control technique for choppers}

For the proper functioning of the multi-motor power system . It developed 5 choppers, each with the design criteria previously established in the previous session.

The intention of this development is operation natural of the transistors. Each transistor operates at the frequency and hardness cycle established in the datasheet. The operation frequency is 20kilohertz. The maximum pulse width is 20 microseconds. The transistors arranged in a parallel configuration. Each transistor connected to the DC motor.

The control signal is multiplexed in time so that each transistor operates separately at the set frequency and pulse width defining in the datasheet, this means that while the motor receives a duty 
cycle close to one hundred percent, each transistor will have a duty cycle corresponding to fifth part (figure 6).

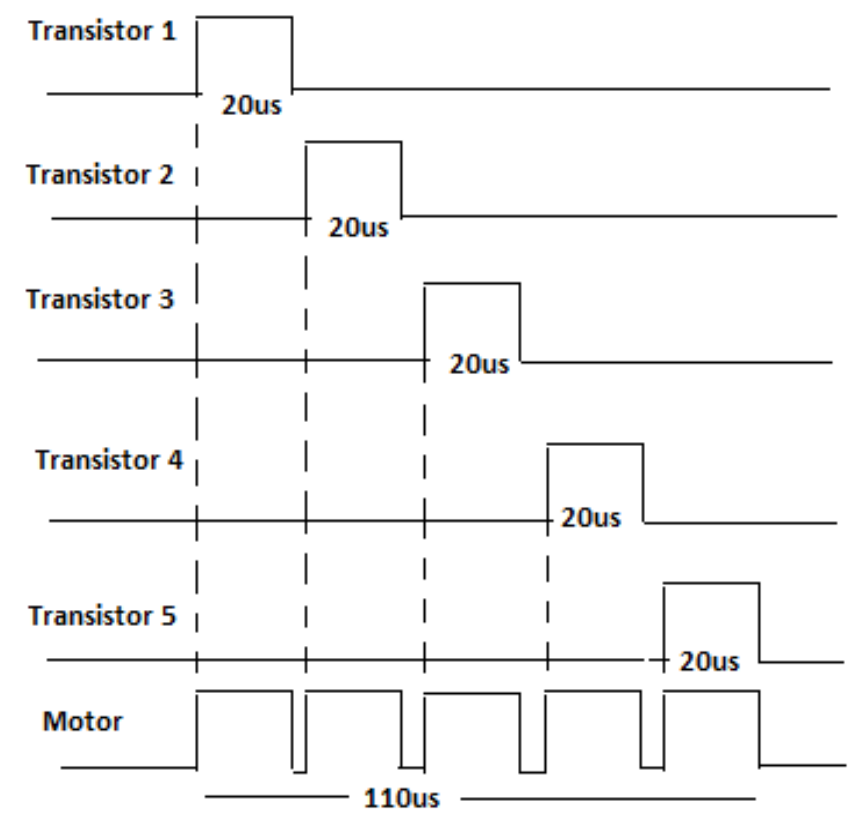

Fig. 6: Multiplexation in the time: shots to transistors and power applied to motor

\section{Data analysis}

The electric car was in tests for 2 months. The tests were flat terrain. The intention is to test the reliability of the power system and the performance of the electric car. The current that requires at certain times the motors is high ( $>>80 \mathrm{~A})$.

The multi-motor power system used a performance of 120 hours. It did not have any technical design failure of the card or temperature problems in the power transistors. The technique of time multiplexing for the excitation of the choppers is optimum. It reflected in the signal quality obtained at the output of the power transistor (figure 7)

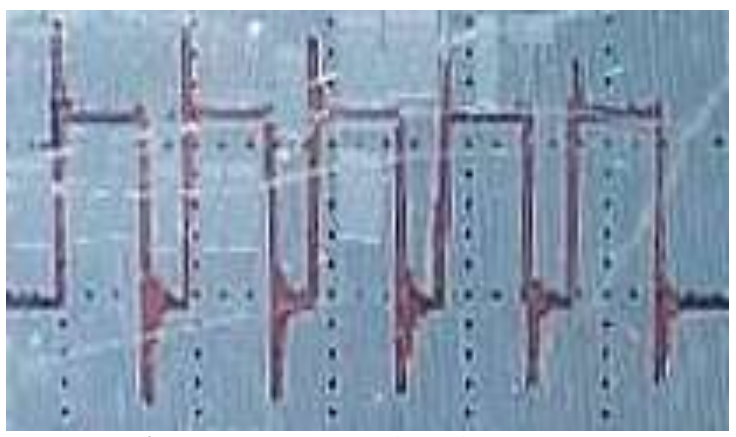

Fig. 7: Output signal of Mosfet transistors

The car performance presents in table 1. It shows the behavior of multi-motor power system. The tension expresses as a function of the changes of the car. The voltage programmed by PWM to dose the energy applied to electric motors.

Table 1: Voltage levels for each position of the gearbox

\begin{tabular}{|l|l|}
\hline March & $\begin{array}{l}\text { Average voltage in } \\
\text { driving tests (Volts) }\end{array}$ \\
\hline Neutral & 12 \\
\hline First & 14 \\
\hline Second & 16 \\
\hline Third & 18 \\
\hline Fourth & 20 \\
\hline
\end{tabular}

Significant changes in currents observed generating great demands on the power system (table 2).

The consequences that unleash these current magnitudes is the variation of temperature.

The maximum temperature is $45^{\circ}$ Celsius. This temperature does not affect the performance of transistors.

Table 2: Current levels for each position of the gearbox

\begin{tabular}{|l|l|l|l|l|}
\hline \multirow{2}{*}{ March } & \multicolumn{4}{|l|}{ Average current in driving tests (Amperes) } \\
\cline { 2 - 5 } & No load & $\begin{array}{l}\text { With } \\
\text { two } \\
\text { people }\end{array}$ & $\begin{array}{l}\text { With } \\
\text { four } \\
\text { people }\end{array}$ & In curves \\
\hline first & 32 & 80 & 81 & 85 \\
\hline Second & 36 & 100 & 110 & 114 \\
\hline Third & 50 & 108 & 120 & 125 \\
\hline Fourth & 46 & 114 & 128 & 135 \\
\hline
\end{tabular}

In addition, the speed of the car measures for each change applied in the proofs (table 3 ).

The car can be viable in an urban environment in which maximum speed allowed is 45 kilometers per hour.

Table 3: Electric car speed

\begin{tabular}{|l|l|}
\hline March & Average speed $(\mathrm{Km} / \mathrm{h})$ \\
\hline First & 10 \\
\hline Second & 18 \\
\hline Third & 30 \\
\hline Fourth & 45 \\
\hline
\end{tabular}

Additionally, the power supply is composed of 6 batteries of the deep cycle of gel with a nominal voltage of 12 volts and current $150 \mathrm{amps}$. The total weight is $280 \mathrm{~kg}$.

\section{Conclusion}

With the present project, the used car adapted with electric motors and accessories.

The performance is similar to a conventional car in typical routines of the city at speeds not exceeding $45 \mathrm{~km} / \mathrm{h}$.

The alimentation module is limited and weighed to the point that the batteries weigh the average of five people.

In spite of this, the flat surface tests developed with two and four people.

It observed there are no appreciable changes in the current consumption with a crew of two people or a crew of fourth people.

The power module, it has been developed through the evolution of various prototypes in which transistor heating problems have been corrected by adapting the snubber network and noise in the trigger device by implementing a ground plane in the circuit.

The multi-motor power system obtained an optimal response due to following aspects:

The adequacy of the shots to the typical operating curves using the technique of control by multiplexing in time.

The connecting five choppers in parallel.

\section{References}

[1] Le Treut, H., R. Somerville, U. Cubasch, Y. Ding, C. Mauritzen, A. Mokssit, T. Peterson and M. Prather «Historical Overview of Climate Change Science». Cambridge University Press, Cambridge, United Kingdom and New York, NY, USA., 2007.

[2] G. J.-M. Jos G.J. Olivier, «Trends in Global CO2 emissions: 2016 report,» Netherlands Environmental Assessment Agency, The Hague, 2016.

[3] T. Jayaraman, «The Paris Agreement on Climate Change: Background, Analysis and Implications, » Review of Agrarian Studies, vol. 1, no. 3, pp $42-59$, 2015. 
[4] The society of motor manufacturers and traders limited, «New car CO2 Report 2017,» SMMT driving the motor industry, Londres 2017.

[5] M. F. B. G. A. P. R. P. A. P. Á. M. R. L. R. S. C. Luis Gilberto Mu rillo, «Política nacional de cambio climático: documento para tomadores de decisiones,» Ministerio de Ambiente y Desarrollo Sostenible, Bogota, 2017.

[6] D. P. A. C. R. B. Muhammed F. Rahman, «Power Electronics Handbook,» Elsevier, Cambridge, 2018

[7] H. J. J. C. Peng Hemeng, «Analysis for the EMI measurement and propagation path in Hybrid Electric Vehicle,» IEEE Information Technology, Networking, Electronic and Automation Control Conference, vol. 1, $\mathrm{n}^{\mathrm{o}} 1$, pp. 1087 - 1090, 2016

[8] Z. E.-H. F. K. A. A. M. A. G. O. Tabbi Wilberforce, «Developments of electric cars and fuel cell hydrogen electric cars,» International Journal of Hydrogen Energy, vol. 42, $\mathrm{n}^{\circ} 40$, pp. 25695 25734, 2017

[9] H. X. W. L. Y. L. L. L. Maobing Li, «The structure and control method of hybrid power source for electric vehicle,» Energy, vol. $112, \mathrm{n}^{\circ}$ octubre, pp. 1273-1285, 2016

[10] M. B. T. B. Philipp Hanemann, «Effects of electric vehicle charging strategies on the German power system,» Applied Energy, vol. $203, n^{\circ}$ octubre, pp. 608-622, 2017.

[11] S. A. J. I. K. Zeina Bitar, «Modeling and Simulation of Series DC Motors in Electric Car,» Energy Procedia, vol. 50, n 50, pp. 460 470, 2014

[12] M. F. Ashby, «Chapter 10: Case Study: Electric Cars,» de Materials and Sustainable Development, Waltham, Elsevier, 2016, pp. 151166

[13] E. X. L. C. Charalampos Marmaras, «Simulation of electric vehicle driver behaviour in road transport and electric power networks,» Transportation Research Part C: Emerging Technologies, vol. 80, $\mathrm{n}^{\circ}$ Julio, pp. 239-256, 2017

[14] N. Y. J. J. Saharul Arof, «Series motor four quadrants drive DC chopper for low cost, electric car: Part 1: Overall,» IEEE International Conference on Power and Energy, vol. 1, n ${ }^{\circ}$ 1, pp. 342 - 347 , 2014

[15] A. P. T. D. R. Abdullah Assegaf, «Dynamic response analysis of Permanent Magnet Brushless DC Motor drives for city electric car based on Matlab/Simulink,» Joint International Conference on Rural Information \& Communication Technology and ElectricVehicle Technology, vol. 1, $\mathrm{n}^{\mathrm{o}}$ 1, pp. 1 - 5, 2013

[16] Y. K. H. S. Feng Yaojing, «Research of interior permanent magnet brushless DC motor for electric vehicles,» International Conference on Electrical Machines and Systems, vol. 1, no 1, pp. 1074 - 1079, 2013

[17] M. Wens, M. Steyaert, Design and Implementation of FullyIntegrated Inductive DC-DC Converters in Standard CMOS, Ana$\log$ Circuits and Signal Processing Springer, pp 27 - 63, 2011

[18] James E. Vinson AND J. J. Liou , , «Electrostatic Discharge in Semiconductor Devices: Protection Techniques,», proceedings of the IEEE, vol. 88, No 12, pp 1878 - 1900, 2000.

[19] Robin Getz, Bob Moeckel , «Understanding and Eliminating EM in Microcontroller Applications,», Texas Instruments, 30 p, 1996.

[20] Tom Williamson , «Designing Microcontroller Systems for Electrically Noisy Environments »Intel , 26 p, 1993 